\title{
Enzyme based soil stabilization for unpaved road construction
}

\author{
Rintu Renjith ${ }^{1}$, Dilan Robert $^{1}$, Andrew Fuller $^{2}$, Sujeeva Setunge $^{1}$, Brian O’Donnell ${ }^{3}$, and \\ Robert Nucifora ${ }^{2}$ \\ ${ }^{1}$ Civil Engineering, RMIT University, Australia \\ ${ }^{2}$ Infrastructure Services, Downer Group Ltd, Australia \\ ${ }^{3}$ Center for Pavement Excellence Asia Pacific
}

\begin{abstract}
Enzymes as soil stabilizers have been successfully used in road construction in several countries for the past 30 years. However, research has shown that the successful application of these enzymes is case specific, emphasizing that enzyme performance is dependent on subgrade soil type, condition and the type of enzyme used as the stabilizer. A universal standard or a tool for road engineers to assess the performance of stabilized unbound pavements using well-established enzymes is not available to date. The research aims to produce a validated assessment tool which can be used to predict strength enhancement within a generalized statistical framework. The objective of the present study is to identify new materials for developing the assessment tool which supports enzyme based stabilization, as well as to identify the correct construction sequence for such new materials. A series of characterization tests were conducted on several soil types obtained from proposed construction sites. Having identified the suitable soil type to mix with the enzyme, a trial road construction has been performed to investigate the efficiency of the enzyme stabilization along with the correct construction sequence. The enzyme stabilization has showed significant improvement of the road performance as was evidenced from the test results which were based on site soil obtained before and after stabilization. The research will substantially benefit the road construction industry by not only replacing traditional construction methods with economical/reliable approaches, but also eliminating site specific tests required in current practice of enzyme based road construction.
\end{abstract}

\section{Introduction}

Unpaved roads cover more than $56 \%$ of the Australian road network [1] and are increasingly being constructed in rural countries due to less construction cost. Major issues of unpaved roads include loss of fines in the form of dust, wasting of natural resources caused by washouts and landfills, detriment water courses, aquifers and ecology and most importantly cause vehicular damage and safety issues. Chemical stabilization using nontraditional additives has been identified as an effective solution for such issues in contrast to the application of traditional stabilizers such as lime, cement or flyash. This is mainly due to environmental and economic viability of traditional stabilizers that can result high emissions of greenhouse gases along with unbearable costs in their applications. Enzyme 
based soil stabilization is a form of non-traditional chemical stabilization that has been successfully used in road construction for the past 30 years. Despite its use for the last 3 decades, there has been no universal standard or tool that practicing engineers can use to assess the performance of unbound pavement stabilized with enzyme additives. This study aims to produce a validated assessment tool which can be used to predict strength gain within a generalized statistical framework. Within this broad scope, the present study aims to identify a suitable enzyme which can stabilize fine grained soils. Firstly, a series of characterization tests were conducted on several soil types obtained from proposed construction sites. Having identified the suitable soil type to mix with the enzyme, the trial road construction has been performed to investigate the efficiency of the enzyme stabilization along with the correct construction sequence. The enzyme stabilization has showed significant improvement of the road performance as was evidenced from the test results which were based on site soil obtained before and after stabilization.

\section{Literature Review}

The application of enzymes for road construction dates back to 1981 when it was used to stabilize a half a mile of road in Oklahoma [2]. Since its introduction in the road construction industry, this form of stabilizer is gaining significant exposure. However, the industry is not readily accepting this form of stabilizer due to improper documentation and its unfamiliarity.

There are many reported studies in literature that suggest the advantage of enzyme stabilization for road construction. Scholen [2] reported sites such as Red Maple road of Oucahita National forest that benefitted from enzyme treatment which did not show any signs of damage such as rutting even during the log hauling season when the adjacent untreated sections were prone to severe rutting. Field application of enzymes have also been proved efficient in many cases in nations like Brazil, China, India, Malaysia, South Africa and USA, resulting in increase in load bearing capacity of roads and durability along with significant decrease in road maintenance costs despite harsh weather conditions [310]. However, there are several other studies in literature highlighting less efficiency of enzyme based stabilization. Scholen [2] showed that, even though the stabilization has been effective in many sites, non-effective outcomes have also been resulted due to treated layer failure from improper construction techniques. Bergmann [11] identified the failure to attain strength on the harsh conditions such as the dropping of temperature to -3.9 degrees at one tested site. Moloisane and Visser [12] highlighted excessive wet conditions as a plausible reason to the failure and inconsistent results during trial road construction. Therefore, it is evident from the literature that the use of enzymes in road construction needs better understanding by careful characterization of enzyme and soil using laboratory tests prior to apply in the field conditions.

Traditionally, the application of enzymes in the field is followed after a series of testing conducted under laboratory conditions. The purpose of these tests can be various, such as to investigate the response of the proposed trial mix as specified in the manufacturer's specification, find out the optimised mix design or to explore the efficiency of new materials ( \& design proportions) for applying into road construction. The oldest laboratory tests on enzyme treated soils date back to early 1990's where Khan and Sarker [13] tested the effects of adding enzyme to fly ash stabilised soil. The tests showed significant increase in strength of soil when compared to lime stabilized soil. There are studies that showcased strength improvement range of 136 to 1800 times the original CBR [14]. However, similar to the field applications, few studies highlighted that the treatment of soils with additives can also give non-satisfactory results or minor strength increase. Tingle, Newman [15] treated low plastic clayey soils with enzyme, but only improved the stabilized soil strength 
by $4-6 \%$. Rauch, Katz [16] also found out that the stabilized samples had not showed satisfactory results due to sample preparation method. In general, the literature suggests that the inefficiency of stabilization can be due to factors such as flaws in sample preparation, inadequate curing, and inappropriate soil type for stabilization $[16,17]$

As highlighted above, the efficiency of stabilization can be either positive or negative, depending on many factors such as soil type, soil initial condition, enzyme type, enzyme amount, curing, temperature, etc. As the primary purpose of many studies involved stabilization is to identify the positive spectrum for a given condition, the mechanism of stabilization needs to be explored at the first place. Even though the results of enzyme application have been reported extensively in literature, the mechanism of stabilization process has been rarely identified in majority of studies. Out of very few identified mechanisms, the most accepted hypothesis suggests that the enzyme based stabilization is through the process of organic encapsulation. In this process, the positively charged enzyme particles encapsulates the organic molecules in the negatively charged clay particles which have high affinity for water. With this process, the clay's double layer water as well as the affinity for water decreases. The clay particle is more stable and binds well with other clay particles causing aggregation and reduction of surface area [2]. This hypothesis was further supported by Rauch, Harmon [18] with experiments which showcased the increase in d-spacing, expansion of clay layer, reduction of pore sizing and surface area as shown in Fig. 1

a.

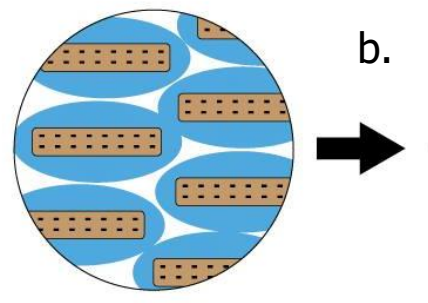

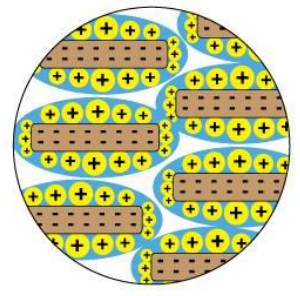
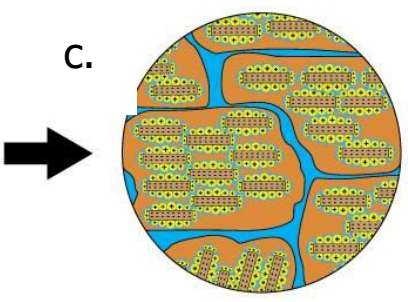

Fig. 1. (a.) Natural clay particle with high affinity for water (b). Organic encapsulation decreasing double layer water and affinity for water (c). The more stable clay sheets bind together with other clay particles causing aggregation and reduction of surface area

\section{Methodology}

The objectives of the current study were achieved using laboratory experiments, field construction and pavement performance assessment. Firstly, laboratory tests were conducted on the basis of several soils to identify the physical characteristics of the soils obtained from various construction sites in Melbourne. Having identified the suitable soil as per to manufacturer's guideline, the field construction has been performed on the basis of enzyme specification. A mechanistic pavement design has been conducted using CIRCLY to investigate the limit state functionality of the constructed road [1]. The constructed pavement has also been tested using Japanese formula to validate the functionality of the constructed road [1]. This section provides details of lab testing (including properties), field construction stages and the overview/properties of analytical models used for road performance assessment. 


\subsection{Soil Characteristics}

A series of laboratory tests was conducted on different soil types to investigate the suitable soil for soil stabilization. Reference tests such as Gradation tests, Atterberg tests and compaction tests were performed to obtain physical characteristics of soils as per the relevant Australian Standards. Four soil types were tested for this study, which are labelled as S1, S2, S3 and S4 in this manuscript. Results of the reference tests are summarised in Table 1.

Table 1: Reference test results of the soils tested in current study

\begin{tabular}{|c|c|c|c|c|c|c|}
\hline Soil ID & USCS $^{1}$ & $\begin{array}{c}\text { \% less } \\
\text { than } 75 \boldsymbol{\mu}\end{array}$ & $\mathbf{L L}^{\mathbf{2}}$ & $\mathbf{P L}^{\mathbf{3}}$ & $\mathbf{P I}^{\mathbf{4}}$ & OMC $^{\mathbf{5}}$ \\
\hline S1 & SM & 13.2 & 29 & 13 & 16 & 5 \\
\hline S2 & SM & 4.6 & \multicolumn{3}{|c|}{ Non-Plastic } & 6.6 \\
\hline S3 & SC & 34 & 21 & 13 & 8 & 6.2 \\
\hline S4 & SM-SC & 16 & 28 & 18 & 10 & 6.1 \\
\hline \multicolumn{7}{|l}{ Unified Soil Classification, ${ }^{2}$ Liquid Limit, ${ }^{3}$ Plastic Limit, ${ }^{4}$ Plasticity Index, ${ }^{5}$ optimum } \\
moisture content
\end{tabular}

Based on the current specification of the utilized enzyme, soil types S3 \& S4 can be identified as the most suitable soil which works efficiently with the selected enzyme (enzyme specification identifies the suitable soil as having PI between 6-15 for effective stabilization[19]). Therefore, S3 \& S4 has been selected for the field test which has been demonstrated in the section 3.3.

\subsection{Enzyme used in the study}

Eko-Soil was used as the stabilizer in this study. The product, which is a natural, non-toxic and bio-degradable product, is a stabilizing agent that helps in the reduction of voids in the soil layer and in turn increases the load bearing capacity of the soil.

\subsection{Trial Road Construction}

Two trial road sections of an existing unsealed trial road (Fig. 2) was constructed using enzyme stabilization with the materials S3 and S4 as identified from Table 1. This section summarises the construction stages of the unsealed road construction. Prior to the construction, the trial road subbase was shaped, trimmed and compacted to at least $98 \%$ of proctor compaction by measuring the field density of compacted soil using nuclear gauge and manual dry density measurements. Imported materials from the sites having soil type S3 and S4 were added to the pavement at a depth of $150 \mathrm{~mm}$ at different sections of $300 \mathrm{mx} 5.5 \mathrm{~m}$ which was selected to be stabilized as the pavements base/wearing layer. Soil samples, before and after adding the enzyme were collected in a sealed plastic bags and delivered to the labs for conducting the mechanical testing (i.e. CBR). The trial road construction was performed on the selected sections of the road (Fig. 3a) in 5 different stages as described below: 


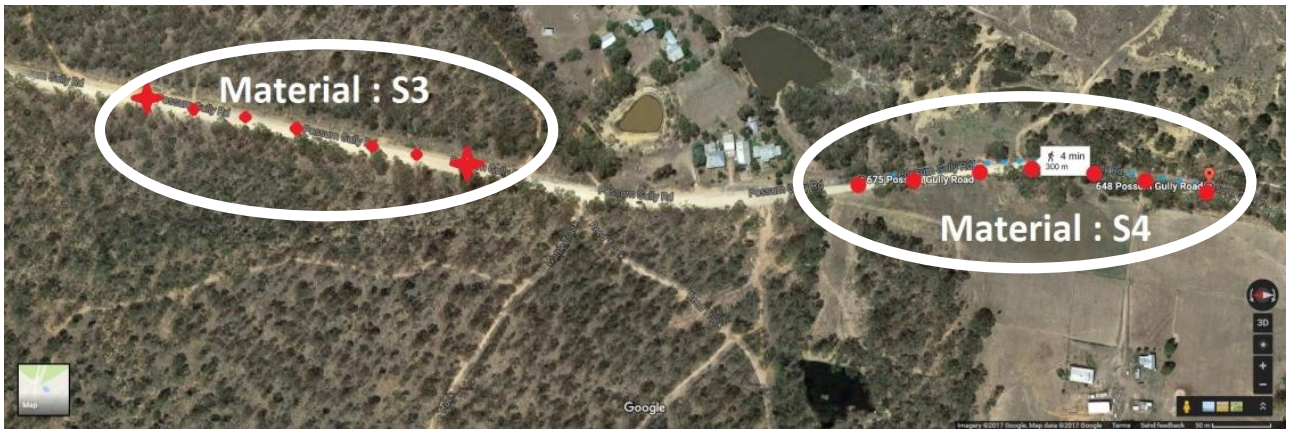

Fig. 2. Construction site showing trial road sections (Image from Google Earth, 3706'34.7"S $\left.143^{\circ} 40^{\prime} 09.8^{\prime \prime} \mathrm{E}\right)$

\section{Construction Stage 1: Ripping}

The compacted pavement was ripped to $150 \mathrm{~mm}$ depth with the grader, which allowed the moisture levels to be easily adjusted, increase the depth of enzyme penetration and to reduce the possibility of losing enzymes through drainage (Fig. 3b).

\section{Construction Stage 2: Moisture Adjustment}

The moisture of the pavement was adjusted via passing the dribble bar from the watercart over the soil several times until it was deemed to be just before optimum moisture content (OMC) as determined by a squeeze test by the enzyme supplier's consultants onsite (Fig. $3 c)$. The controlled water content was based on the selected enzyme percentage ( $1 \%$ by dry weight) and the OMC of the selected soil type.

\section{Construction Stage 3: Dilution of Enzyme and Spreading}

After assessing the moisture content of the pavements material, the pre-calculated diluted enzyme was added into the pavement material using the same watercart. The dilution rate used in the current study was 1:500. Once the enzyme was added from the watercart, it was evenly spread over the pavement for uniform bed preparation (Fig. 3d)

Construction Stage 4: Mixing the Enzyme

Once the enzyme was sprayed into the wet soil, soil + water + enzyme were mixed thoroughly using the stabilizer (Fig. 3e).

Construction Stage 5: Compaction, Shaping and Final Moisture Adjustment

Finally, the pavement was compacted by passing the multi-tyre and smooth drum rollers several times over the pavement. Moreover, shaping was performed by the grader until a cross fall of at least $6 \%$ was achieved (Fig. 3f).

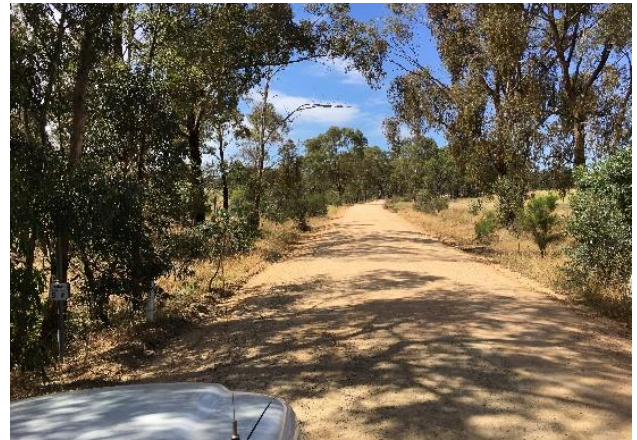

(a) S4 trial road section before stabilization

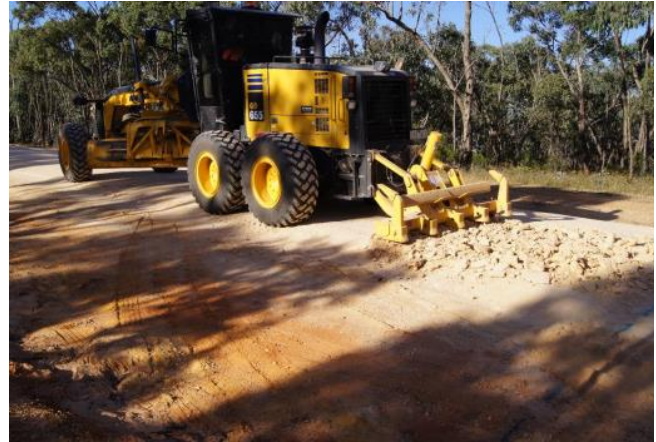

(b) Stage 1: Ripping of trial section with grader 


\section{EACEF 2017}

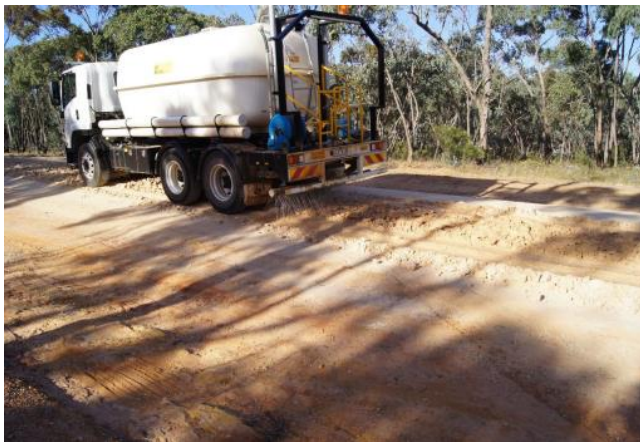

(c) Stage 2: Moisture Adjustment with watercart

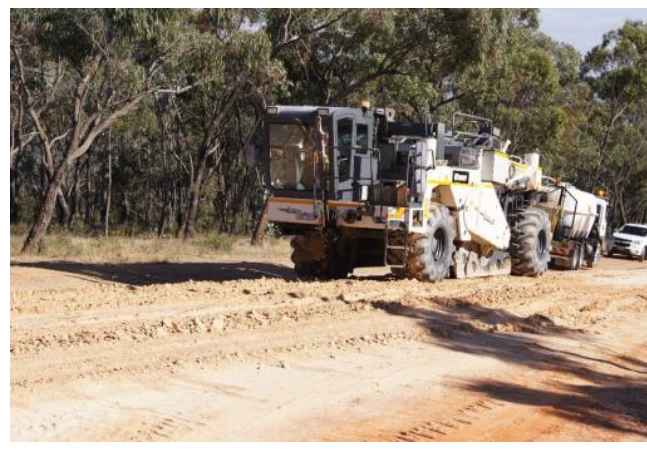

(e) Stage 4: Mixing of soil and enzyme

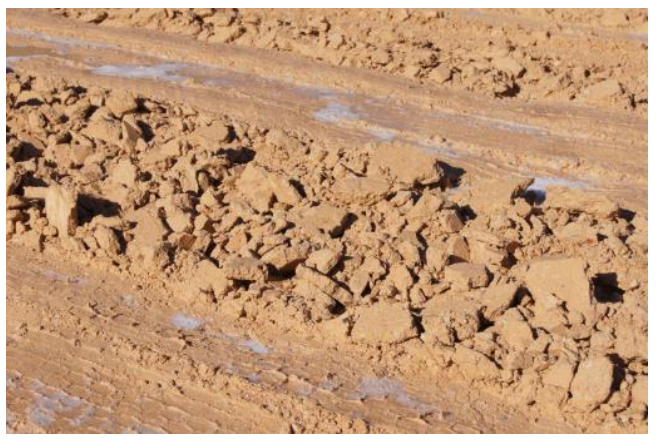

(d) Stage 3: Soil after dispensing the enzyme

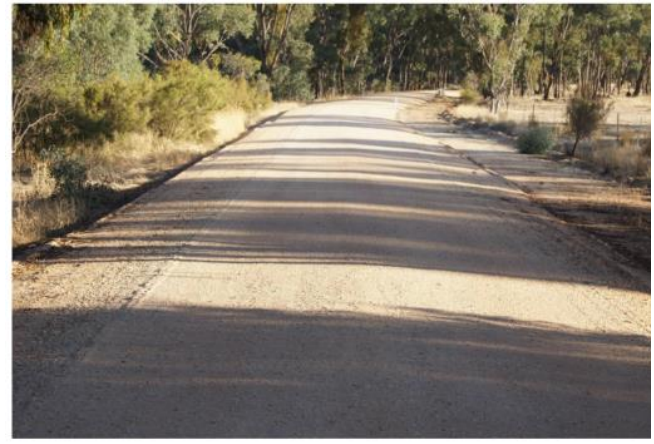

(f) Stage 5: Finished road section after shaping and compaction

Fig. 3. Construction stages of trial road construction

\subsection{CIRCLY and Japan Model}

\section{CIRCLY}

A mechanistic pavement design has been conducted in this study using CIRCLY to investigate the allowed traffic load which satisfies the strain and rutting limits as specified in the Austroad standards [1]. Results from CIRCLY analysis provide an estimate of the pavement layer depth required to sustain traffic loads. The geometry for the analysis and the input parameters are showed in Fig. 4 and Table 2.

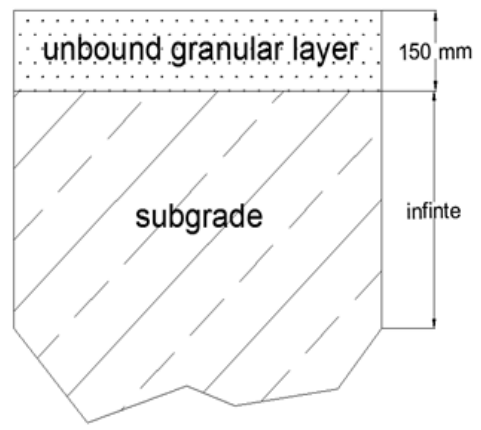

Fig. 4. CIRCLY pavement diagram 
Table 2 CIRCLY input parameters

\begin{tabular}{|c|c|}
\hline $\begin{array}{l}\text { Design Equivalent Standard Axle } \\
\text { (DESA) }\end{array}$ & $4 \times 10^{31}$ \\
\hline Project Reliability & $85 \%^{2}$ \\
\hline Traffic Multiplier & $1^{3}$ \\
\hline Subgrade Thickness & $0.00^{4}$ \\
\hline \multicolumn{2}{|c|}{ 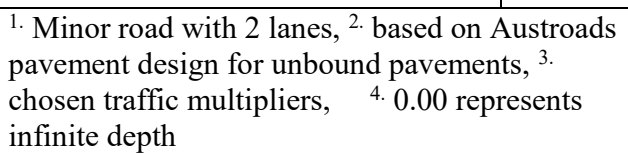 } \\
\hline
\end{tabular}

\section{Japanese Model}

This model refers to the Japan Road Association formula which determines the equivalent subgrade strength [1]. This model determines the required CBR to be achieved by pavement layers for an average weighted CBR of 5 which is currently being used as a rule of thumb by road contractors from experience. The equivalent subgrade strength is based on the following equation.

$$
C B R_{m}=\left[\frac{\sum_{i} h_{i} C B R_{i}{ }^{0.33}}{\sum_{i} h_{i}}\right]^{3} \leq 20
$$

Where $C B R_{i}$ is the CBR value in layer thickness $h_{i}$ and $\sum h_{i}$ is taken up to a depth of $1.0 \mathrm{~m}$

\section{Results}

\subsection{Field road performance}

A careful monitoring of the moisture and dry density was conducted to ascertain that the construction follows the expected construction standards. Table 3 summarises the monitoring results. It was observed that the construction was able to achieve reasonable moisture ratios, but unable to meet $98 \%$ proctor density as specified by Vicroads Code of Practice RC 500.20 [20]. This could be mainly due to the use of multi-tyre roller instead of a vibrating roller.

Table 3 Moisture and density monitoring of the trial road construction

\begin{tabular}{|c|c|c|}
\hline Soil ID & Moisture Ratio (\%) & Density Ratio (\%) \\
\hline S3 & 98.0 & 92.5 \\
\hline S4 & 96.5 & 89.5 \\
\hline
\end{tabular}

CBR tests were performed as per AS1289.6.1.1 [21] on the basis of samples obtained from the road, before and after stabilization. Samples were obtained at two sections of the road where soil type S3 and S4 were utilized. Fig. 5 summarises the test results from the lab tests. As it can be seen, the stabilization has been significantly effective to increase the road strength from prior stabilization to post-stabilization (increase of $69 \mathrm{CBR}$ and $101 \mathrm{CBR}$ respectively). 


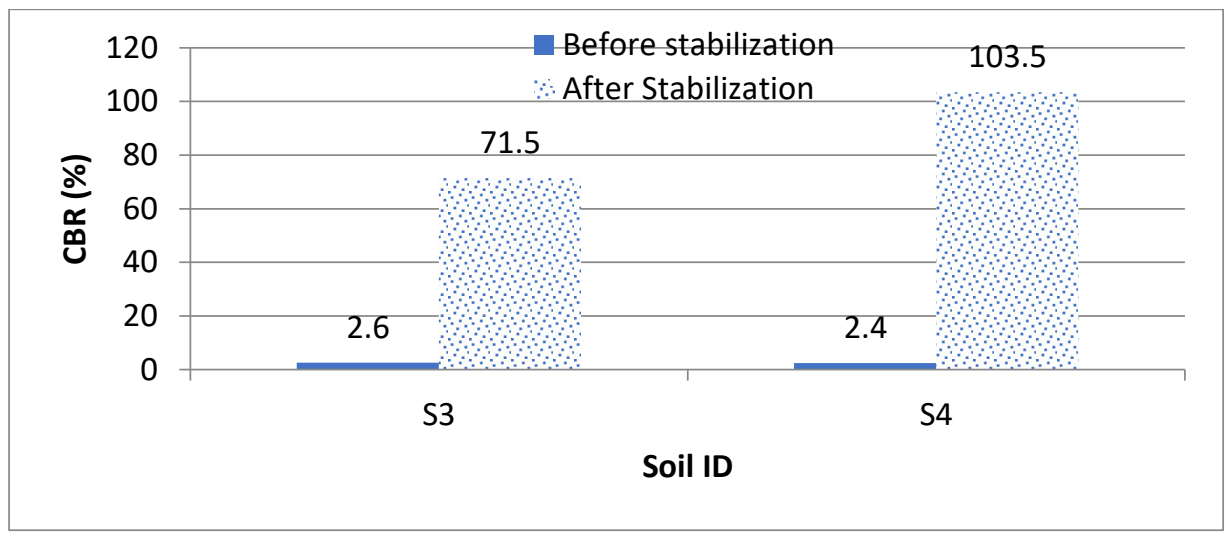

Fig. 5. CBR of the soils obtained from the trial road

\subsection{CIRCLY and Japan Model Results}

CIRCLY analysis was conducted on the designed pavement to satisfy the cumulative damage factor $(\mathrm{CDF}<1)$ of the designed pavement as specified in Austroads [1]. Table 4 summarises the results of the analysis, which shows the minimum depth required for the treated base layer as $350 \mathrm{~mm}$ and $369 \mathrm{~mm}$ for S3 and S4 respectively. They revealed substantial reduction of material (22\% and $23 \%$ reduction for S3 \& S4 respectively) for the base layer from prior-stabilization to post-stabilization.

Table 4. Results of CIRCLY analysis

\begin{tabular}{|c|c|c|c|}
\hline $\begin{array}{c}\text { Soil } \\
\text { ID }\end{array}$ & $\begin{array}{c}\text { Thickness of layer (before } \\
\text { stabilization) }\end{array}$ & $\begin{array}{c}\text { Thickness of layer (after } \\
\text { stabilization) }\end{array}$ & $\begin{array}{c}\text { Difference in } \\
\text { layer depth }\end{array}$ \\
\hline S3 & $451 \mathrm{~mm}$ & $350 \mathrm{~mm}$ & $101 \mathrm{~mm}$ \\
\hline S4 & $479 \mathrm{~mm}$ & $369 \mathrm{~mm}$ & $110 \mathrm{~mm}$ \\
\hline
\end{tabular}

Results also revealed that the required thickness for stabilized layers from the standard mechanistic pavement design tool is substantially higher than what has been adopted (i.e. $150 \mathrm{~mm}$ ) in current trial road construction. However, the weighted average CBR for the treated soil obtained from the Japanese model (Table 5) exceeds 5.0 which is currently being used as a rule of thumb by road contractors from experience. Therefore, it can be seen from the current study that the treated soil provides adequate strength to satisfy the constructed road to operate as lightly trafficked unbound road. The road is currently being monitored for its performance under operational traffic loads to verify the effectiveness of the selected enzyme stabilization.

Table 5. Results of Japan Formula

\begin{tabular}{|c|c|c|c|c|}
\hline Material & Layer & Depth (m) & $\begin{array}{c}\text { CBR per } \\
\text { layer }\end{array}$ & $\begin{array}{c}\text { Weighted } \\
\text { average CBR }\end{array}$ \\
\hline \multirow{2}{*}{$\begin{array}{c}\text { S3(non- } \\
\text { treated) }\end{array}$} & Unbound layer & 0.15 & 2.6 & 2.57 \\
\cline { 2 - 4 } & subgrade & 0.85 & 2.6 & \\
\hline S3 (treated) & Unbound layer & 0.15 & 71.5 & 5.63 \\
\cline { 2 - 4 } & subgrade & 0.85 & 2.6 & \\
\hline $\begin{array}{c}\text { S4 (non- } \\
\text { treated) }\end{array}$ & Unbound layer & 0.15 & 2.4 & 2.38 \\
\hline
\end{tabular}




\begin{tabular}{|c|c|c|c|c|}
\hline & subgrade & 0.85 & 2.4 & \\
\hline \multirow{2}{*}{ S4 (treated) } & Unbound layer & 0.15 & 103.5 & \multirow{2}{*}{6.11} \\
\cline { 2 - 4 } & subgrade & 0.85 & 2.4 & \\
\hline
\end{tabular}

\section{Conclusion}

The current study presented the efficiency and the correct use of new enzyme in the construction of unsealed road. Several soil types have been analysed to identify the suitable soil to mix with the enzyme in the field application. The enzyme content and dilution mass ratio has been selected on the basis of the current enzyme specification. CBR test results for samples obtained from the constructed road showed a significant increase in the road strength from prior-stabilization to post-stabilization. Though the predictive analysis performed based on standard mechanistic tool suggested increased layer treatment thickness, analysis results based on a practising model revealed that the constructed stabilized road exceeds the minimum specifications required. While this response shows over conservatism of existing standards, the results have potential to identify suitable/economical construction material and the correct construction sequence of unsealed road with the use of the selected material. The research is being continued at present to identify most suitable mix-design for the new enzyme within a generalized statistical modelling framework, incorporating the factors such as soil type, enzyme content, dilution mass ratio and organic content of soil. The results from this research will cater road construction industry for implementing road infrastructure at a reduced cost, but with enhanced road performance.

Authors would like to acknowledge the support from Centre for Pavement Excellence Asia Pacific (CPEAP), Central Goldfield Shire and Downer Ltd for conducting trial road constructions in this research. Authors would also like to thank Mr Malcolm Styles of Engineering Management Styles for sharing valuable resources and expertise during the trial road construction.

\section{References}

1. Austroads, Austroads pavement design guide.. (2001),

2. D.E. Scholen, Non-standard stabilizers. (1992).

3. Ants revolutionize road construction in South America, in Toronto Star., Toronto Star: Toronto, Ont. p. C5. (1990)

4. A. Hitam, A.Z. Yusof, and O. Samad. Soil stabilizer for plantation road,(1999)

5. R. Brazetti and S.R. Murphy. Objective performance measurement of actual road sites treated with an Organic Soil Stabilizer (2000).

6. R. Thompson, R. Johnson, and J. Sedgwick, Road Stabilization Report, in Tooele County, Utah.. p. 17. (2002)

7. A. Campbell and D. Jones, Soil Stabilization in Low-Volume Roads. T.R.R. Journal. 2204: p. 172-178. (2011)

8. Y.J. Li, L. Li, and H.C. Dan, Study on Application of TerraZyme in Road Base Course of Road. A.M.M.,. 97-98: p. 1098. (2011)

9. A.R. Shankar, R. Mithanthaya, and B. Lekha. Laboratory studies on bio-enzyme stabilized lateritic soil as a highway material (2012).

10. W.S. Guthrie, D.O. Simmons, and D.L. Eggett, Enzyme Stabilization of Low-Volume Gravel Roads. T.R.R. Journal,. 2511: p. 112-120. (2015)

11. R. Bergmann, Soil stabilizer for use on universally accessible trails. (2000). 
12. R. Moloisane and A.T. Visser, Evaluation of the strength behaviour of unpaved road material treated with electrochemical-based non-traditional soil stabilisation additives. J.S.A.I.C.E. 56(1): p. 28-39. (2014)

13. L.I. Khan and M. Sarker, Enzyme enhanced stabilization of soil and fly ash. Fly ash for soil improvement. Asce geotechnical special publication. 36, (1993.)

14. K.P. Isaac, P. Biju, and A. Veeraragavan. Soil Stabilization using Bioenzymes for Rural Roads. (2003)

15. J. Tingle, et al., Stabilization mechanisms of nontraditional additives. T.R.R. Journal, (1989): p. 59-67

16. A.F. Rauch, L.E. Katz, and H.M. Liljestrand, AN analysis of the mechanisms and efficacy of three liquid chemical soil stabilizers. Research Report 1993-1: VOLUME. Work,. 1. (2003)

17. D.J. Robert, R. Renjith, S. Setunge, B. O'Donnell, D. Hewawasmge and E. Tan, Assessing the stabilizing mechanisms of unbound road pavements,. (2016)

18. A. Rauch, et al., Measured Effects of Liquid Soil Stabilizers on Engineering Properties of Clay. T.R.R. Journal 1787: p. 33-41. (2002)

19. Manual, E.-S.T. (2015)

20. Vicroads, in $R C 500.20$ Code of Practice. (2014)

21. Standards, A., AS 1289.6 Methods of testing soils for engineering purposes, in 6.1.1 Soil strength and consolidation tests - Determination of California Bearing Ratio of a soil. (2014) 